\title{
How Accessible and Usable Are Our Neighbourhood Playgrounds for Children Who Have Mobility Restrictions or Use Mobility Devices?
}

\author{
Beverlie Dietze
}

\begin{abstract}
Beverlie Dietze, $\mathrm{PhD}$, is an assistant professor in the Department of Child and Youth Study at Mount Saint Vincent University in Halifax, Nova Scotia. Her research interests include outdoor play environments for children and early learning and child care professional staff development models. She was educated at Sheridan College, the University of New Brunswick, St. Francis Xavier University, and the University of Toronto. Email: Beverlie.Dietze@MSVU.ca
\end{abstract}

Many municipalities across Canada have created neighbourhood playgrounds that are intended to offer children and families a place to play, meet other families, and participate in activities that support the establishment of a healthy lifestyle. Yet the structural designs of many of these neighbourhood playgrounds restrict or eliminate children or adults who have mobility restrictions from participating at them. Structural barriers include the placements of the sidewalks, pathways, ground surface, and elevated frameworks around the playground equipment. This paper discusses the results of examining the municipal neighbourhood playgrounds in one suburban community in Nova Scotia in relation to accessibility and usability features for children or adults with mobility restrictions. Adjusting the current accessibility and usability designs of neighbourhood playgrounds becomes increasingly important in our quest to increase children's physical activity levels, promote play, and model inclusive practices for all members of society. Environmental barriers contribute to social barriers and social exclusion. Accessibility to public space is a legal right and must be viewed as a community's moral and ethical obligation. It is critical that all citizens in a community experience inclusive practices and a sense of dignity in their daily living experiences.
In Nova Scotia, where do the children play? The province prides itself as being "Canada's Ocean Playground." For many, these three words bring about images of children and families outdoors, near water, and playing in the sand. Visualizing the beach, we may imagine active, healthy children who are running, jumping, swimming, building, or climbing. When the word "ocean" is removed and we think of playgrounds, different images may emerge. Instead we may think of children using swings and climbers; we may recall squeals of joy or young voices asking for "just one more minute." We may have visions of neighbourhood playgrounds that attract children and families, or we may picture underutilized spaces where few children gather.

Increasing children's levels of physical activity is a priority for governments and organizations associated with child development and wellness. Studies suggest that outdoor play is widely considered a key component in increasing children's physical activity levels, reducing obesity, and developing healthy, active lifestyles (Gubbels et al., 2011). The reality of hurried lifestyles and changing societal values, however, are contributing to the challenge of families developing active lifestyles. Active lifestyles can be even more challenging for children with mobility restrictions or children who have adults in their lives with mobility issues, especially if they depend on their neighbourhood playground as a space for, and a source of, active play. Most of us assume that we now live in an inclusive society. Inclusion is "the philosophy that all people have the right to be included with their peers in age-appropriate activities throughout life" (Miller \& Schleien, 2006). Examining places where children and families may gather to play in their community from an accessibility perspective is important because of the relationship between motor movement abilities, physical activity, and social inclusion. Upon examination of many community places, the environmental barriers that prevent children or adults with mobility restrictions from participating in everyday life situations become evident.

Being excluded from everyday life situations is not a new phenomenon. In spite of the early studies of Goffman (1963) and decades of research and activism that followed, there continue to be social and environmental barriers that preclude accessibility for all. Instead of a model of accessibility, researchers such as Michalko (1998), Titchkosky (2008), and others identified that a social model of disability has been created by society due to the many types of barriers that exclude individuals with disabilities from being able to access public space or participate in common daily living experiences (Oliver, 1996; Prellwitz, Tamm, \& Lindqvist, 2001). When barriers prevent children and families from accessing spaces, such as neighbourhood playgrounds, an imbalance in society is created (Lawton, 1980). This imbalance may contribute to individuals with a disability having 
feelings of inequality, and it reinforces the types of struggles that individuals with disabilities face and live with on a daily basis.

Children have the right to play. This right is highlighted in the United Nations Convention on the Rights of the Child (UNCRC; United Nations High Commission for Human Rights, 1989). The Convention contains a number of articles which are "specifically relevant to children's access to and experiences of their local environment and their access to play" (Cole-Hamilton, Harrop, \& Street, 2002). Articles 31 and 23 are most relevant to this study. Article 31 states that:

Every child has the right to rest and leisure, to engage in play and recreational activities appropriate to the age of the child and to participate freely in cultural life and the arts.

And Article 23 indicates that:

A mentally or physically disabled child should enjoy a full and decent life, in conditions which ensure dignity, promote self-reliance and facilitate the child's active participation in the community.

Canada ratified the UNCRC in 1991. Canada also released the Canadian Standards Association (CSA) play spaces accessibility document in 2007, which establishes minimum accessibility requirements for newly constructed and existing playgrounds that require upgrading. Increasingly more research is available that highlights the disrespect shown to people with disabilities when their social right of having access to places is denied, is publicized by signs, or is different from non-disabled citizens (Michalko, 2009; Titchkosky, 2008). Changes to accessibility practices notwithstanding, there are still many environments in various parts of Canada where children with mobility restrictions are excluded. To have the neighbourhood playground be such a space is paradoxical, especially in light of the public perception of inclusive practice. In one Nova Scotia municipality, for example, the jurisdiction's website states their mission as providing quality inclusive leisure services, facilities, and programs for their citizens. Unfortunately, many of the neighbourhood playgrounds in that municipality exhibit structural design features that inhibit or exclude individuals with mobility restrictions from being able to access or use the play space.

In this article, I highlight the results of a study that examined the accessibility, usability, and barriers of neighbourhood playgrounds at the entrance points and pathways to the equipment in one suburban Nova Scotia community. Because social inclusion and access to public space is a right of all citizens, this study is viewed as a starting point to facilitate change to the playgrounds by outlining the current conditions that, by design, exclude children or adults with mobility restrictions. Specifically, the study is intended to provide insight into the extent to which the entrances to playgrounds, the pathways within them, the ground surfaces, and the transfer systems from the perimeter of the playground to the play equipment may support or inhibit children or adults with mobility restrictions in using neighbourhood playgrounds. Such environmental barriers may negatively impact children's social and physical wellness, play options, interaction with others, and sense of belonging in society. Environmental barriers have a direct correlation to the social disability model which, when present, is inequitable and reduces the overall wellness of communities.

\section{Neighbourhood Playgrounds}

Several studies reveal that outdoor play spaces influence how and where children play (Bjorklid, 2005; Fjortoft, 2001; Moser \& Martinsen, 2010). The people and spaces in children's environments shape their physical activity and depth of play (Dietze \& Kashin, 2012; Miles, 2008). The level of comfort that adults have with neighbourhood playgrounds influences the quality and type of play in which children engage (LoukaitouSideris \& Sideris, 2010). For example, adults who have positive feelings toward neighbourhood play spaces intentionally create opportunities for children to actively engage in play that supports exploration, experiential play, and risk taking (Dietze \& Kashin, 2012). If adults feel ambivalent or negative toward the play space, they either avoid the play space or rush children to complete their play episode so that they may move to a space that offers more comfort to them or their children.

Neighbourhood playgrounds are intended to be play spaces for children and families to gather to socialize and engage in active play with others. Play is the foundation on which children can increase their levels of physical activity, and it contributes to them gaining a sense of freedom, independence, and improved self-concept (Frost, 2006; Rivkin, 1995). Conversely, if children with restricted mobility do not have access to quality group play experiences that include physical play, they may not develop the same level of skills in independence, experimentation, problem solving, communicating with peers, or taking risks that are necessary for their social, emotional, cognitive, and physical development (Bilton, 2002; Ouvry, 2003). Physical play influences children's social connections in terms of developing playmates and becoming part of social groups (Segal, Mandich, Polatajko, \& Cook, 2002). Neighbourhood playgrounds can be a pivotal place for user groups to participate in informal networking, explore community and cultural identity, and model inclusive practices (LoukaitouSideris \& Sideris, 2010; Miles, 2008; Woolley, Armitage, Bishop, Curtis, \& Ginsborg, 2006).

Children strive to be accepted into their peer group. Research studies suggest that when children with mobility issues do not have access to the same play environments as their peers, they feel different from their peers. When children are not part of a peer group, they may develop feelings of not 
fitting in or social isolation; they may feel victimized or discriminated against, that they are not the equal of their peers; or, they may experience stigmatization from their peers (Nabers \& Badawi, 1997; Segal et al., 2002), which can lead to feelings of loneliness (Poulsen, Ziviani, Cuskelly, \& Smith, 2007). As a way to protect themselves, children tend to choose to withdraw or avoid having contact with their peers (Segal et al., 2002). The absence of peers changes the quality of play, often leading children to become more dependent on adults as their play partners or to predominately engage in solitary play. As well, as a way to protect children from feeling inadequate or at risk of being bullied or teased, it is not uncommon for families to develop "stigma management techniques," such as avoiding places, people, and situations that contribute to the feelings of difference (Prellwitz, 2007). Prolonged negative feelings and isolation from peers put children at risk of developing psychosocial issues, such as low self-esteem, lack of confidence and self-regulation skills, and interpersonal relationship challenges (Skär, 2002). All children have the right to have access to and be able to use their neighbourhood playground. When access is denied for whatever reason, discrimination occurs.

Prellwitz and Skär (2007) define accessibility as one's ability to approach, enter, and exit the playground in a functional manner. Similarly, the Canadian Standards Association (2007) describe an accessible route as "a continuous unobstructed pathway from the perimeter of the use zone to the equipment" (p. 3). Playground usability is identified as the person being "able to move around, be in and use the environment on equal terms with others" (Prellwitz \& Tamm, 1999, p. 145). Neighbourhood playgrounds that incorporate accessibility and usability elements into their design support users of the play space in building a foundation for healthy and active lives, which in turn builds healthy communities (Barovick, 2010).

Drawing on the definitions of accessibility and usability as identified by Prellwitz and Skär (2007), this study examined the neighbourhood playgrounds in one suburban community in Nova Scotia. Looking at the accessibility and usability features of these neighbourhood playgrounds brings awareness to how children with mobility restrictions or children who have adults in their lives with mobility issues may be included or excluded from play opportunities within their home community. This study may provide a forum for municipalities and communities to examine their neighbourhood playgrounds for accessibility and usability features and, as importantly, to determine if and how socially inclusive practices are being exhibited. The findings may also facilitate discussions about how neighbourhood playgrounds need to be redesigned to model inclusive practices.

\section{The Study}

The main purpose of this study was to examine the accessibility and usability features of the municipal playgrounds located in one suburban community to determine how each playground space supports or restricts children or adult caregivers with mobility restrictions in accessing or using the playground. The research was exploratory in nature because only limited data are available about neighbourhood playgrounds in Nova Scotia or about children with mobility restrictions using neighbourhood playgrounds in Nova Scotia.

Based on a literature review conducted on accessible play spaces and the definitions of accessibility and usability identified by Prellwitz and Skär (2007), a set of questions on accessibility and usability was developed that focused on the entrance to the playground, the pathways within the playground, the ground surfaces, and the transfer systems from the perimeter of the playground to the play equipment.

The municipal website was used to locate the neighbourhood playgrounds. The website identified nineteen neighbourhood playgrounds in the community. Upon examination of these playgrounds, it turned out that two playgrounds listed on the municipal site did not exist. In addition, one playground only had tennis courts and another was a naturalized forest play space with a walking trail. This reduced the study sample to fifteen municipal playgrounds, four of which were located adjacent to or on school properties.

Using direct observation at the fifteen municipal playgrounds, six core questions were answered in relation to how entry points, ground surfaces, space for mobility, ramps, and transfer systems impact families using neighbourhood playgrounds. Photos and field notes were taken at each playground. A coding system was developed and used to identify playground accessibility and usability features. Themes were identified and compared with the notes taken in relation to the accessibility and usability definitions outlined by Prellwitz and Skär (2007).

\section{Findings}

The presentation of findings is aligned with the research questions formulated to examine the accessibility and usability of the playgrounds.

\section{Accessibility}

The accessibility features of neighbourhood playgrounds influence how children approach play, their motivation to play, their play options, and the depth of active play in which they engage. The accessibility factors of the municipal playgrounds were examined in relation to parking space, the sidewalks/pathways to the playground and from the entrance of the playground to the playground equipment, and entrance restrictions.

Is there a parking lot for vehicles that would support children or adults with mobility issues to be able to safely exit the vehicle, acquire their mobility device, and move toward the playground? 
One important aspect of children and families using neighbourhood playgrounds is being able to drive to the playground and have adequate space to park. Four of the fifteen playgrounds had designated parking spaces. Onstreet parking was available at seven playgrounds. One playground had parking space for one car, but the allocated space had a slight incline which could cause difficulty for individuals exiting the vehicle, especially if mobility devices were required to support them entering or exiting the vehicle. Another playground had a flat, gravelled parking space that could accommodate twenty cars. The three remaining playgrounds, adjacent to local schools, had paved, flat parking lots available.

Are there sidewalks/pathways leading up to the playground, and is there a hard surface that would support a child or adult using a mobility device?

The presence of sidewalks in neighbourhoods, the pathways leading to playgrounds, and the surface cover used on pathways have a significant impact on whether individuals with mobility devices can manoeuvre their devices to get to the playgrounds. Eight playgrounds did not have designated sidewalks or pathways that led to the playground. There were sidewalks on the opposite side of the street at three of the playgrounds. Two playgrounds had standard cement sidewalks on the same side of the street as the playground. None of the sidewalks had curb cuts that would allow individuals using mobility devices, such as a wheelchair, to manoeuvre from the street level to the sidewalk or from the sidewalk to the playground.

One playground, located on school property, had a solid surface pathway that led to the playground from the parking lot. Another playground, located in a mature part of the community, had two entrances. The first entrance had an off-street parking lot with a gravel surface located approximately 59 metres from where the playground equipment was located.
Users would be required to follow a winding, sloped gravel path down the hill to the playground. The second entrance to this playground was located on a side street approximately 51 metres from the playground equipment. There was no path from the street leading to the playground equipment. There was an approximate 1.5-metre incline from the street entrance to the playground equipment. The ground cover from the street entrance to the playground equipment area was grass.

Are there sidewalks/pathways from the entrance of the playground to the playground equipment, and is there a ground surface that would support the use of a mobility device?

Children or adults using mobility devices require pathways and ground surface covers that provide them with a feeling of stability. Examination of the pathways from the entrance of the playground to the playground equipment revealed that only four of the fifteen playgrounds had sidewalks/pathways leading to the playground equipment. Three of these playgrounds were located in school spaces. As indicated previously, the one playground with two entrances had gravel or grass pathways.

The ground surfaces leading to the play equipment varied from grass to pea gravel to hard surface pavement. Of the fifteen playgrounds examined, $46 \%$ had pea gravel as a ground surface leading up to and around the playground equipment. Twenty-six percent of the playgrounds had pavement as their ground surface, and $20 \%$ had grass as the ground surface leading to the playground equipment. One playground had a man-made rubberized solid surface material leading to the playground.

Are there entrance restrictions such as gates or posts that may limit access to children who use mobility devices?

An important aspect for children or adults with restricted mobility is if the gates or posts erected at the entrance and exit of playgrounds are wide enough to accommodate mobility devices. The playground that had two entrances (one at the top of the hill and the other on the side street at the bottom of the hill) had a padlocked gate and fence at the entrance at the bottom of the hill. The gate opening was approximately 88 centimetres in width. This size of opening would restrict mobility devices such as wheelchairs from entering through the gate. The remaining playgrounds had unrestricted open spaces at their entrances.

\section{Usability}

The design of the neighbourhood playground as a play space influences if and how children or adults with mobility issues use the playground (Prellwitz \& Skär, 2007). The usability factors of the municipal playgrounds were examined in relation to elevated paths and transfer systems, ground pathways within the playground area, surface coverings, and the open space available for manoeuvring mobility devices.

Are there elevated paths or systems in place that allow children with mobility devices to get to the playground equipment?

Elevated paths or systems are intended to provide individuals with mobility aids to move about the play space; they connect play spaces and offer access to the equipment in the playground. In this case, all fifteen playgrounds lacked elevated pathways or transfer systems that would support children with restricted mobility in connecting to the playground equipment or open space. Another complication observed was that twelve of the fifteen playgrounds had elevated wooden borders around the perimeter of the playground equipment that were between 10 and 20 centimetres above ground level. There were no transfer systems in place that would support children with mobility devices getting over the borders to access the playground equipment.

Are there ground paths within the play space that support a child with mobility 
devices to move around and have access to all aspects of the play space?

The purpose of ground paths within the play space is to support children with mobility devices in having access to the core play space so that they may engage in a variety of play experiences (Prellwitz, Tamm, \& Lindqvist, 2001). All fifteen playgrounds examined lacked ground paths within the play space that would support individuals with restricted mobility or devices to access all parts of the play space. Although the playground that had the man-made rubberized ground covering did not have designated ground paths within the play space, the ground surface made it feasible for children to access more aspects of the play space than the other playgrounds examined.

Does the surface covering around the play structure support a child with mobility devices to have the opportunity to move around the play structure?

The surface coverings around a play structure support or inhibit how children with mobility devices explore and engage within the play space. The playground with the man-made rubberized solid surface around the play equipment would support children or adults with mobility devices to get to the playground equipment. All other playgrounds had pea gravel or a combination of grass and pea gravel around the playground equipment. In most instances, the pea gravel completely surrounded the play structures. If children could get to the play structures, the pea gravel would interfere with them easily manoeuvring mobility devices such as wheelchairs, crutches, or canes.

Is there manoeuvring space around the play structure that would allow for children with mobility devices to make 180-degree turns if required?

Children with restricted mobility require space to manoeuvre their mobility devices in a variety of directions. Small spaces around play structures reduce children's ability to move in and out of a space comfortably or to make the 180-degree turns that may be required. The playground that had the man-made rubberized ground surface covering had sufficient space and a surface covering that would support children being able to make adequate turns. Two other playgrounds had sufficient space for children to manoeuvre their mobility devices, but had pea gravel as the surface covering, which would also inhibit the ease with which a mobility device could be manoeuvred. Twelve playgrounds did not have adequate space for children with mobility devices to make 180-degree turns.

\section{Discussion}

According to researchers such as Baker and Donnelly (2002) and Heath, McGuire, and Law (2007), the barriers in children's environments have a stronger influence than their disability on their participation in play. Michalko (1998) and others who have studied the social model of disability reinforce this perspective by suggesting that the disability is not the main issue for the individual. Participation is influenced more by how society views disabilities and creates barriers, thereby excluding people with disabilities from engaging in daily living experiences (Imre, 1997; Oliver, 1996). To break the social model of disability, neighbourhood playgrounds need to be accessible to all citizens.

The results of this study indicate that in the community where this study occurred, significant environmental design flaws exclude potential users with restricted mobility from accessing their neighbourhood playground. The findings indicate that only one playground had some environmental features that would make it accessible to children with mobility restrictions. The remaining playgrounds lack appropriate ground surfaces on pathways and around equipment, and appropriate transfer systems. These limitations clearly imply, from a societal positioning perspective, that there is not fair or equitable accessibility for all and that social exclusion exists. Social exclusion has many negative implications for community development and for children and their development, and it works against accepting and celebrating diversity and individuals with differences.

When children are faced with environmental or social barriers, such as not having the freedom to access the playground and choose where to play, what to play on, and with whom, they are in essence being segregated from their social network. Yet playing with peers is an important developmental requirement (Dietze \& Kashin, 2012; Stanley, 2011). This means that just through presenting these environmental conditions, children with restricted mobility have fewer opportunities to participate in interactions, experiences, or experimentation with their physical and social environments than do their peers without disabilities. It would further appear that the lack of accessibility to neighbourhood playgrounds is in direct violation of Articles 23 and 31 of the UNCRC, as well as a variety of laws, such as the Accessibility for Ontarians Disability Act, that have been legislated to protect individuals from discrimination. This study raises important issues about the physical inaccessibility of the playgrounds in this particular community and how "exclusive practices" rather than "inclusive practices" are being modelled by this community.

Neighbourhood playgrounds can be the hub of activity for children and families that positively influences individual, family, and community wellness. Based on the results of this study, there would appear to be a lack of understanding of the importance of all citizens having access to public space and what environmental barriers implicitly or explicitly communicate about being an inclusive society.

Removing the physical environmental barriers is achievable. Many communities have been guided by universal design principles created by the Center for Universal Design (1997) at North Carolina State University. Playgrounds that adapt these principles model equitable use (so 
that the design supports people with diverse abilities), flexibility in use (so that the play space supports a wide range of individual abilities), low physical effort (so that manoeuvring around the play space may be done with comfort, ease, and a minimum of fatigue), and reasonable size and space (so that individuals are supported regardless of mobility and body structure).

Inclusive playgrounds may be unique in their presentation, but what they should have in common is that all users can be active and feel included, safe, and able to participate in play, similar to their peers. These types of play spaces are designed to intentionally facilitate bringing together physical play with social connections and social play, which leads to increasing the play options for people of diverse abilities, interests, race, gender, and culture. This model of inclusion breaks down the barriers that have perpetuated the social disability model.

Municipalities could benefit from becoming familiar with and adapting universal design concepts in their decisionmaking processes around playgrounds. If these concepts were employed, the environments and the materials within the playground would only be present if they were usable by all people, without adaptation or specialized designs being required (Christophersen, 2002; Ringaert, 2002). Municipal staff may be required to examine and change some attitudes, engage in different levels of problem solving and visioning, and seek input from users of neighbourhood play spaces. Research has shown that involving children and adults with mobility restrictions in planning play spaces provides valuable information and a better understanding of how simple design features can change the functionality and accessibility of the play space (Barnes, Mercer, \& Shakespeare, 1999). Adopting universal design concepts may bring forth positive attitudinal changes that would promote open access to environmental space and equality to all citizens of a neighbourhood, regardless of their ability or disability (Iwarsson \& Stahl, 2003), which in turn supports both the physical and psychological needs of all users (Ringaert, 2002).

Bringing together experts, such as early childhood education specialists, early intervention specialists, and occupational therapists, as well as parents and children with mobility restrictions could lead to the creation of a new blueprint for accessible neighbourhood playgrounds, thus support the development of active, healthy communities. Creating educational tool kits that provide key attributes of accessible playgrounds could be helpful for communities, municipalities, and school settings. Expanding municipal websites to include specific sections on accessible playground principles and models of accessible playgrounds may further support communities in redesigning their play spaces so that they are inclusive. The availability of educational programming on accessible playgrounds, in a variety of formats, could support individuals and groups seeking up-to-date information on accessible playgrounds. Such information may help parents, community leaders, municipal planners, and others to determine how to ensure that the UNCRC is adhered to in their community and that all children have access to their neighbourhood playground.

Finally, if it is agreed that it is in the best interest of society to have accessible and usable environmental space such as neighbourhood playgrounds for all citizens, how do we move this agenda forward? Do we need specific legislation to upgrade the playgrounds? How do we provide the public with education to rethink the messages we send when exclusive, rather than inclusive, environmental space is within our community settings? It is time to rethink neighbourhood playgrounds and design them so that they are active, accessible play spaces for children and adults alike. This could be an important strategy in creating healthy communities that celebrate diversity and differences.

\section{Limitations}

This study provides a snapshot of neighbourhood playgrounds in one suburban community. The sample was small and focused only on accessibility and usability in relation to gaining access to the playground space from the perspective of children or adults with mobility restrictions. The study did not examine the playground equipment for accessibility or usability features. This is the next phase needed so that playgrounds are adapted to be inclusive. Nevertheless, information obtained from analyzing the playgrounds based on the core questions used in this study suggests that the playground sponsors need to examine public play space relative to inclusive practice, the social disability model, and the UNCRC.

This study did not seek out the opinions of municipal staff responsible for neighbourhood playgrounds or children or adults with mobility restrictions to obtain their perspective on the playgrounds examined. Such information would provide rich data and insight into the current challenges that children with mobility restrictions face in using neighbourhood playgrounds.

\section{Conclusion}

To summarize, it is evident that even though active outdoor play and being part of a community are essential to the development of young children, not all neighbourhood playgrounds are accessible or usable for children or their adult caregivers with mobility restrictions. The fact that the neighbourhood playgrounds examined had pathways, ground surfaces, and wooden borders that would pose a challenge and most likely eliminate children with mobility restrictions from playing there should be a concern to all citizens of the community. Excluding citizens from public space is unacceptable. Investing in inclusive neighbourhood playgrounds can't be seen as an option. Communities have an obligation to advocate for and create social space that 
promotes and celebrates diversity and differences rather than maintaining a social exclusion model.

\section{References}

Baker, K., \& Donnelly, M. (2002). The social experience of children with disability and the influence of environment: A framework for intervention. Disability and Society, 16, 71-85.

Barnes, C., Mercer, G., \& Shakespeare, T. (1999). Exploring disability. Cambridge, UK: Polity.

Barovick, H. (2010, August 9). Building a better playground. Time, 176(6), 45-46.

Bjorklid, P. (2005). Learning and the physical environment: A survey on interaction between learning and physical environment in preschool and school. Stockholm, Sweden: The Authority for School Development.

Bilton, H. (2002). Outdoor play in the early years Management and innovation. London, UK: David Fulton

Canadian Standards Association. (2007). Children's playspaces and equipment. CAN/CSA Z614-07. Etobicoke, ON: Author.

Center for Universal Design. (1997). The principles of universal design. Retrieved from: http://www.ncsu. edu/ncsu/design/cud/about_ud/udprinciplestext.htm

Christophersen, J. (2002). (Ed.). Universal design: 17 ways of thinking and teaching. Oslo, Norway: Husbanken.

Cole-Hamilton, I., Harrop, A., \& Street, C. (2002). Making the case for play: Gathering the evidence. London, UK: National Children's Bureau.

Dietze, B., \& Kashin, D. (2012). Playing and learning in early childhood education. Toronto, ON: Pearson Canada.

Fjortoft, I. (2001). The natural environment as a playground for children: The impact of outdoor play activities in pre-primary school children. Early Childhood Education Journal, 29(2), 111-117.

Frost, J. (2006). The dissolution of children's outdoor play: Causes and consequences. Paper presented at the conference "The Value of Play: A Forum on Risk, Recreation, and Children's Health," Washington, DC, May 31, 2006. Retrieved from: http://cgood.org/assets/ attachments/Frost_Common_Good_-_FINAL.pdf

Goffman E. (1963). Behavior in public places: Notes on the social organization of gatherings. New York, NY: Free Press.

Gubbels, J., Kremers, S., Van Kann, D., Stafleu, A., Candel, M., Dagnelie, P., Thijs, C., \& deVries, N. (2011). Interaction between physical environment, social environment, and child characteristics in determining physical activity at child care. Health Psychology, 30(1), 84-90.

Heath, T., Case, T., McGuire, B., \& Law, M. (2007). Successful participation: The lived experience among children with disabilities. Canadian Journal of Occupational Therapy, 74(1), 38-48.

Imre, R. (1997). Rethinking the relationship between disability, rehabilitation, and society. Disability and Rehabilitation, 19, 263-271.

Iwarsson S., \& Stahl, A. (2003). Accessibility, usability and universal design: Positioning and definition of concepts describing person-environment relationship. Disability and Rehabilitation, 25(2),57-66.
Lawton, M. P. (1980). Environment and aging. Monterey, CA: Brooks/Cole.

Loukaitou-Sideris, A., \& Sideris, A. (2010). What brings children to the park? Analysis and measurement of the variables affecting children's use of parks. Journal of the American Planning Association, 76(1), 89-107.

Michalko, R. (1998). The mystery of the eye and the shadow of blindness. Toronto, ON: University of Toronto Press.

Michalko, R. (2009). The excessive appearance of disability. International Journal of Qualitative Studies in Education, 22(1), 65-74.

Miles, R. (2008). Neighborhood disorder, perceived safety, and readiness to encourage use of local playgrounds. American Journal of Preventive Medicine, 34(4), 275-281.

Miller, K., \& Schleien, S. (2006). A community for all children: A guide to inclusion for out-of-school time. Department of Recreation, Parks \& Tourism. University of North Carolina, Greensboro, NC.

Moser, T., \& Martinsen, M. (2010). The outdoor environment in Norwegian kindergartens as pedagogical space for toddlers' play, learning, and development. European Early Childhood Education Research Journal, 18(4), 457-471.

Nabers, L. A., \& Badawi, M. (1997). Playground interactions for preschool-age children with special needs. Physical \& Occupational Therapy in Pediatrics, $17,21-31$.

Oliver, M. (1996). Understanding disability: From theory to practice. Basingstoke, UK: Macmillan.

Ouvry, M. (2003). Exercising muscles and minds: Outdoor play and the early years curriculum. London, UK National Early Years Network.

Poulsen, A., Ziviani, J., Cuskelly, M., \& Smith, R. (2007). Boys with developmental coordination disorder: Loneliness and team sports participation. American Journal of Occupational Therapy, 61, 463-474.

Prellwitz, M. (2007). Playground accessibility and usability for children with disabilities: Experiences of children, parents, and professionals. Unpublished doctoral dissertation, Lulea University of Technology, Lulea, Sweden.

Prellwitz, M., \& Skär, L. (2007). Usability of playgrounds for children with different abilities. Occupational Therapy International, 14(3), 144-155.

Prellwitz, M., \& Tamm, M. (1999). Attitudes of key persons to accessibility problems in playgrounds for children with restricted mobility: A study in a mediumsized municipality in Northern Sweden. Scandinavian Journal of Occupational Therapy, 6(4), 166-173.

Prellwitz, M., Tamm, M., \& Lindqvist, R. (2001). Are playgrounds in Norreland (Northern Sweden) accessible to children with restricted mobility? Scandinavian Journal of Disabilities Research, 3(1), 56-68.

Ringaert, L. (2002). Universal design and occupational therapy. OT Now. September/October, 28-30.

Rivkin, M. (1995). The great outdoors: Restoring children's rights to play outside. Washington, DC: National Association for the Education of Young Children.

Segal, R., Mandich, A., Polatajko, H., \& Cook, J. V. (2002). Stigma and its management: A pilot study of parental perceptions of the experiences of children with developmental coordination disorder. American Journal of Occupational Therapy, 56, 422-428.
Skär, L. (2002). Disabled children's perceptions of technical aids, assistance and peers in play situations. Scandinavian Journal of Caring Sciences, 16(1), $27-33$

Stanley, E. (2011). The place of outdoor play in a school community: A case study of recess values. Children, Youth and Environments, 21(1), 185-211. Retrieved from: http://www.colorado.edu/journals.cye

Titchkosky, T. (2008). To pee or not to pee. Canadian Journal of Sociology, 33(1), 37-60.

Titchkosky, T. (2009). Disability images and the art of theorizing normality. International Journal of Qualitative Studies in Education, 22(1), 75-84.

United Nations High Commission for Human Rights (1989). Convention on the Rights of the Child, Geneva, Switzerland: Author.

Woolley, H., Armitage, M., Bishop, J., Curtis, M., \& Ginsborg, J. (2006). Going outside together: Good practice with respect to the inclusion of disabled children in primary school playgrounds. Children's Geographies, 4(3), 303-318. 